\title{
Inflammatory cytokine and plasma C- reactive protein response to ketoacidosis in adults with type 1 diabetes: Egyptian multicenter study
}

\author{
Ghada A. Mohamed ${ }^{1}$, Mohamed Z. Abd-Elrahman ${ }^{1}$, Rania Bahriz ${ }^{2}$ and Ahmed Albehairy ${ }^{2,3^{*}}$ (1)
}

\begin{abstract}
Background: In adults with diabetic ketoacidosis (DKA), high plasma levels of C-reactive protein (CRP) and inflammatory cytokines such as interleukin-6 (IL-6) were reported to be sensitive markers of infection. However, elevation of both CRP and the pro-inflammatory cytokines which regulate CRP are probable without infection and may act as indicator of systemic inflammatory response (SIR). So, we wanted to determine if increased plasma CRP levels occur in young patients with severe DKA who do not have clinical evidence of infection and to relate observed changes in CRP level to the pro-inflammatory cytokine levels.

Results: Upon admission of 30 DKA patients with age ranging from 17 to 40 years, we found significant elevation of CRP $(P=0.001)$ and IL-6 $(P=0.001)$ in DKA patients than control group. After resolution of DKA, there was significant reduction in CRP and IL-6 compared to before DKA correction ( $P$ value $=0.054$ and 0.001 ), respectively. There was a significant negative correlation between CRP after correction of DKA and RBCs $(P=0.042)$, and serum $K$ $(P=0.021)$ and between CRP prior to DKA correction and PH $(P=0.025)$.

Conclusions: Patients with DKA without infection had increased levels of CRP and inflammatory cytokines. Intensive insulin therapy has a powerful anti-inflammatory effect that, at the time of DKA improvement, can normalize levels of CRP and inflammatory cytokines, and this beneficial effect is greater for IL-6 than CRP.
\end{abstract}

Keywords: Inflammatory cytokines, CRP, IL6, Diabetic ketoacidosis

\section{Background}

Diabetic ketoacidosis (DKA) is a life-threatening metabolic crisis that may be the first symptom of previously undiagnosed diabetes and occurs predominantly in those with type 1 diabetes or it can also occur in those with type 2 diabetes under certain conditions. DKA results from an absolute insulin deficiency, in response the body switches to burning fatty acids and producing acidic

\footnotetext{
* Correspondence: dr_behiry@mans.edu.eg

Endocrine and Diabetes Unit, Department of Internal Medicine, Faculty of Medicine, Mansoura University, Mansoura, Egypt

${ }^{3}$ Endocrine and Diabetes Unit, Department of Internal Medicine, Mansoura Specialized Medical Hospital, Faculty of Medicine, Mansoura University,

Mansoura, Egypt

Full list of author information is available at the end of the article
}

ketone bodies that cause most of the symptoms and complications [1].

C-reactive protein (CRP) is a type I acute phase response protein synthetized in the liver and regulated by the pro-inflammatory cytokines IL- 6 , IL-1, and TNF- $\alpha$ [2]. CRP has been established as a marker for adverse outcome in acute coronary syndrome, atherosclerosis [3], and ischemic cerebro-vascular accidents [4].

Experimental evidence indicates that CRP induces adhesion molecule expression in endothelial cells [5] and stimulates macrophage production of cytokines at sites of inflammation. Support for a direct role of CRP on endothelial function has been demonstrated by Verma et al. [6], who reported a quenching effect of

\section{Springer Open}

( ) The Author(s). 2020 Open Access This article is licensed under a Creative Commons Attribution 4.0 International License, which permits use, sharing, adaptation, distribution and reproduction in any medium or format, as long as you give appropriate credit to the original author(s) and the source, provide a link to the Creative Commons licence, and indicate if changes were made. The images or other third party material in this article are included in the article's Creative Commons licence, unless indicated otherwise in a credit line to the material. If material is not included in the article's Creative Commons licence and your intended use is not permitted by statutory regulation or exceeds the permitted use, you will need to obtain permission directly from the copyright holder. To view a copy of this licence, visit http://creativecommons.org/licenses/by/4.0/. 
CRP on nitric oxide production. The pleiotropic proinflammatory cytokines that regulate CRP synthesis can directly affect endothelial cell function by increasing capillary permeability [7].

Elevated plasma levels of CRP have been reported to be markers for endothelial cell dysfunction in uncomplicated, well-controlled, type 1 diabetes mellitus (TIDM), and in children with TIDM within the first year after diagnosis [8]. Positive association between CRP and HbA1c has recently been found in adults with diabetes mellitus [9]. CRP and IL-6 have also been reported to be early markers of infection in adults with diabetic ketoacidosis (DKA) and with diabetic hyperosmolar non-ketotic coma (DHNK) [10]. However, counter-regulatory hormones, which are elevated in DKA, have been reported to potentiate IL- 6 in the in vitro production of CRP [11].

Our hypothesis was that both CRP and the proinflammatory cytokines, which regulate CRP, can be elevated without infection in young patients with severe DKA and may serve as a marker for systemic inflammatory response syndrome (SIRS).

\section{Aim of the work}

To determine if increased plasma CRP levels occur in young patients with severe DKA who do not have clinical evidence of infection and to relate observed changes in CRP level to the pro-inflammatory cytokine levels.

\section{Methods}

This prospective cohort study included 30 patients diagnosed as DKA for treatment and follow-up at Intermediate Care Units and 20 age- and sex-matched healthy control subjects.The patients' age range from 17 to 40 years. The included 30 patients fulfilling the American Diabetes Association criteria of DKA [1].
Mild: patient is alert, $7.30 \geq \mathrm{pH} \leq 7.25$ serum $\mathrm{HCO}^{-}$ 15-18 mmol/l

Moderate: mild disturbed conscious level $7.00 \leq \mathrm{pH} \leq$ 7.25, $\mathrm{HCO}^{-}$10-15,

Severe: patient is with disturbed conscious level or $\mathrm{pH}$ is less than $7, \mathrm{HCO}^{-}$is less than 10

These patients undergo measurement of CRP, IL6 prior to, and after correction of DKA after exclusion of acute infection based upon the medical histories and physical examinations.

All patients and controls included in this study are subjected to the following:

I. Full history taking

II. Complete clinical examination

III. Laboratory investigations:

1. Complete blood count (CBC).

2. Blood sugar and urinary acetone.

3. Arterial blood gases.

4. Renal chemistry.

5. Electrolytes (Na, K)

6. CRP, IL6 prior to, and after correction of DKA.

\section{Data collection}

Medical records of all patients were reviewed. The demographic, laboratory, and clinical data were collected.

\section{Measurement of CRP, IL6}

Blood samples were drawn at presentation before initial hydration and after resolution of DKA. Samples for CRP and interleukin-6 were withdrawn into chilled EDTA tubes and immediately centrifuged at $4{ }^{\circ} \mathrm{C}$ at $2500 \mathrm{rpm}$ for $20 \mathrm{~min}$. The plasma was separated and kept at $80^{\circ} \mathrm{C}$ until assayed. Interleukin- 6 was detected by the Assay Max Human Interleukin-6 ELISA (enzyme-linked immunosorbent assay) kit. Plasma CRP was measured, by a high sensitivity ELISA assay. Other laboratory tests

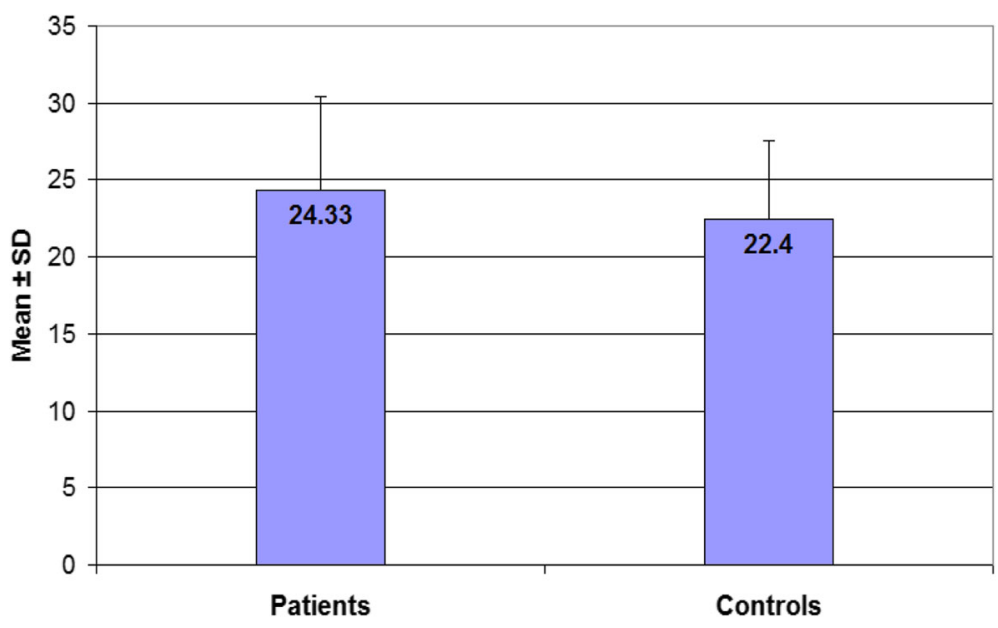

Fig. 1 Mean ages of both patients and controls 


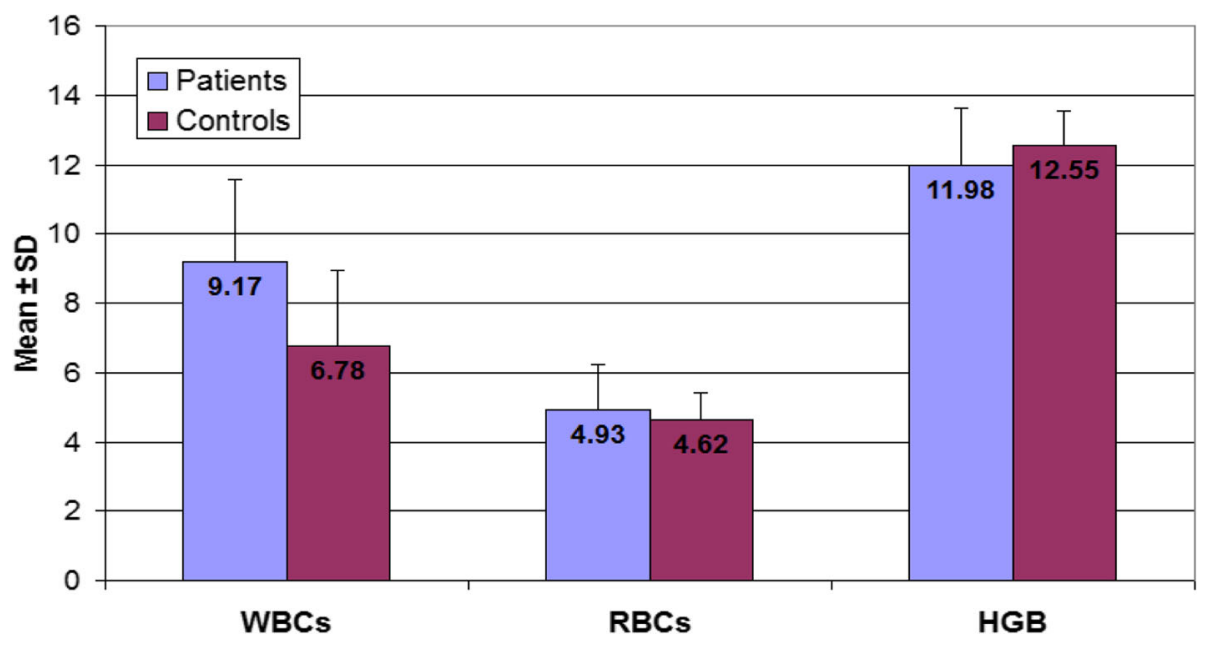

Fig. 2 WBCs, RBCs, and HB level in DKA patients and control

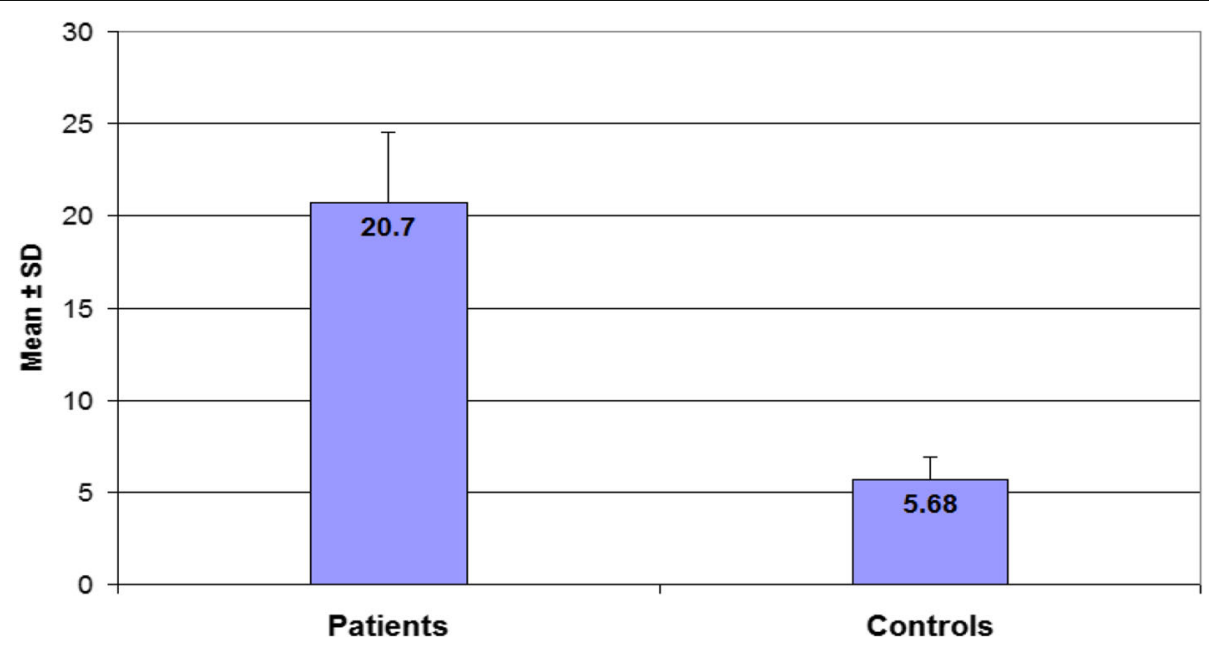

Fig. 3 Random blood sugar among patients and control groups

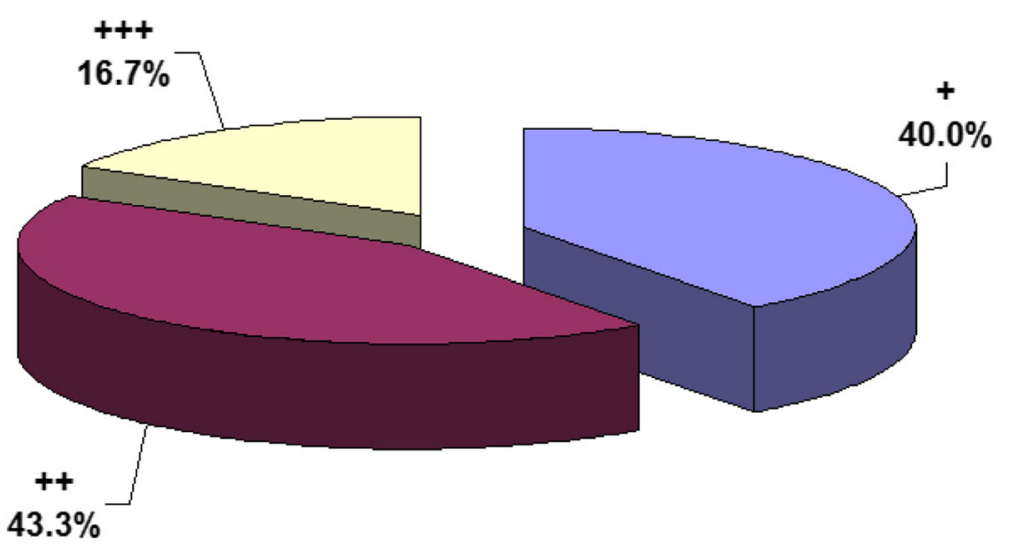

Fig. 4 Acetone grades in patients with DKA 


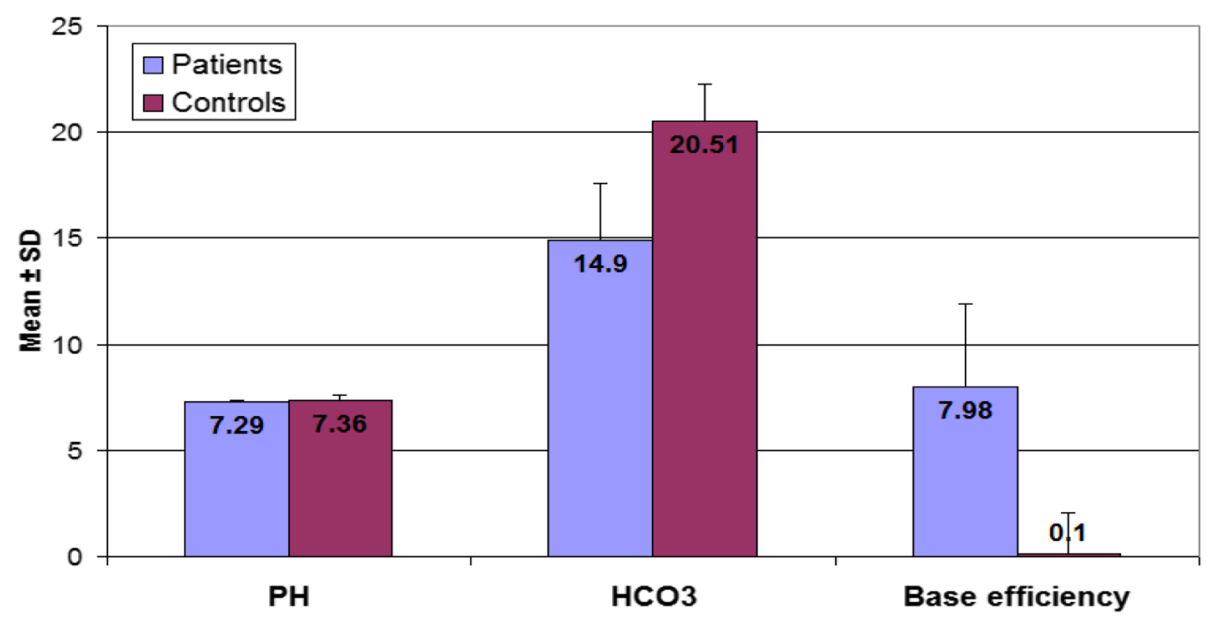

Fig. $5 A B G$ in DKA patients and controls

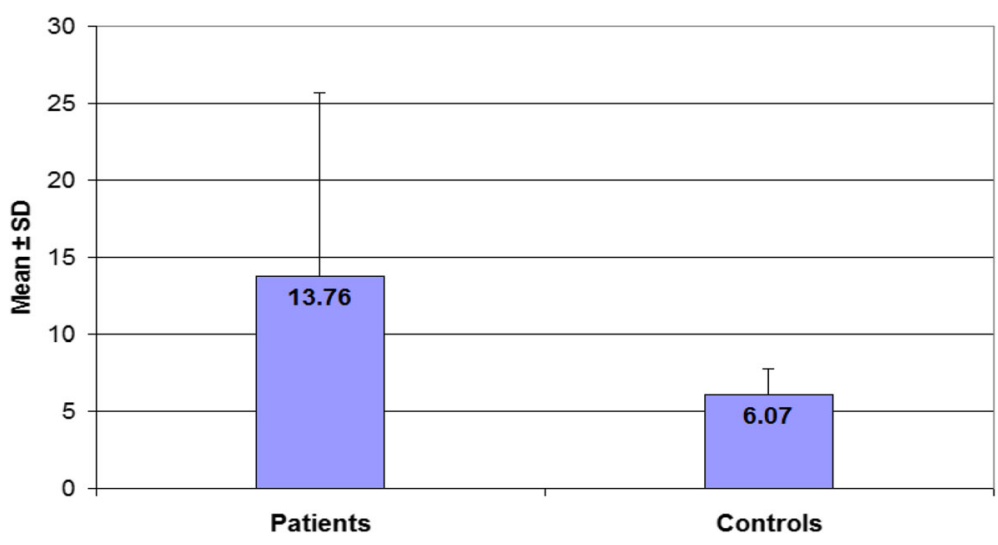

Fig. 6 Urea levels in DKA patients and control

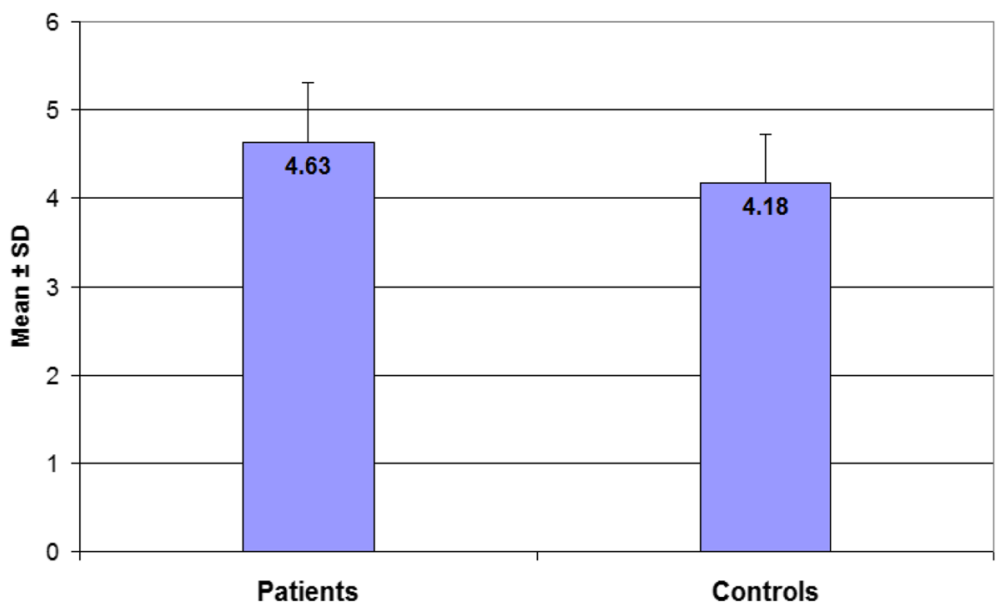

Fig. 7 Potassium levels in DKA patients and controls 
Table 1 CRP before treatment in DKA patients and control

\begin{tabular}{llll}
\hline CRP before & $\begin{array}{l}\text { Patients } \\
(n=30)\end{array}$ & $\begin{array}{l}\text { Controls } \\
(n=20)\end{array}$ & $P$ value \\
\hline Mean \pm SD & $32.27 \pm 35.48$ & $2.02 \pm 1.25$ & 0.001 \\
Median (range) & $12.0(2.0-96.0)$ & $2.0(0.3-5.0)$ & \\
\hline
\end{tabular}

were performed using standard clinical chemistry and hematological procedures in our hospital's clinical laboratories.

\section{Statistical analysis}

The collected data were analyzed by using the Statistical Package for Social Sciences (SPSS/PC/VER 17).

\section{Results}

This prospective cohort study included 30 patients diagnosed as DKA for treatment and follow-up at intermediate care units and 20 age- and sex-matched healthy control subjects. The patients' age range from 17 to 40 years $(24.33 \pm 6.12$ years) (Fig. 1$)$.

There was a highly significant difference in WBCs count, random blood sugar, positive acetone detection in urine, arterial blood gases (ABG), and urea, $(P<0.001)$ and a significant difference in $\mathrm{K}^{+}$level $(P<0.015)$ between DKA patients and control (Figs. 2, 3, 4, 5, 6, 7 and 9, respectively).

There was a highly significant difference in CRP level between DKA patients before treatment and control $(P$ $<0.001$ ) represented in Table 1. Also, there was significant difference in CRP level before and after treatment $(P<0.054)$ as represented in Table 2.

There was a highly significant difference in IL6 level between DKA patients before treatment and control and before and after treatment of DKA $(P<0.001)$ as represented in Tables 3 and 4, respectively.

There was a significant negative correlation between CRP after correction of DKA and RBCs, and serum K and between CRP before correction of DKA and PH $P=$ $0.042 \%, 0.021 \%, 0.025^{*}$, respectively (Figs. 8,9 , and 10, respectively). As regards IL6, no correlation between IL6 before and after correction of DKA with laboratory data as represented in Table 5 .

\section{Discussion}

This prospective cohort study investigated after exclusion of acute infection of the correlation between IL-6,

Table 2 CRP in DKA patients before and after treatment

\begin{tabular}{llll}
\hline CRP & $\begin{array}{l}\text { Before } \\
(n=30)\end{array}$ & $\begin{array}{l}\text { After } \\
(n=20)\end{array}$ & P value \\
\hline Mean \pm SD & $32.27 \pm 35.48$ & $17.13 \pm 24.66$ & 0.054 \\
Median (range) & $12.0(2.0-96.0)$ & $6.0(2.0-96.0)$ & \\
\hline
\end{tabular}

Table 3 IL6 before treatment in DKA patients and control groups

\begin{tabular}{llll}
\hline IL6 before & $\begin{array}{l}\text { Patients } \\
(n=30)\end{array}$ & $\begin{array}{l}\text { Controls } \\
(n=20)\end{array}$ & $P$ value \\
\hline Mean \pm SD & $266.90 \pm 199.10$ & $0.73 \pm 0.74$ & 0.001 \\
Median (range) & $217.7(13.2-764.0)$ & $0.6(0.0-2.0)$ & \\
\hline
\end{tabular}

CRP, and severity of DKA prior to and after correction of DKA. The study included 30 patients diagnosed as DKA for treatment and follow-up at intermediate care units 20 age- and sex-matched healthy control subjects.

The current study showed elevated levels of inflammatory markers in patients with DKA without infection at time of hospital admission while value of inflammatory markers decreased after medical treatment of DKA with insulin intensification. This result matched with Aljada et al. [12] who had suggested the beneficial role of insulin as anti-inflammatory drug in treatment of DKA.

Rolla, 2004 [13] showed that persistent elevation of the blood glucose level is associated with impairment of the levels of inflammatory biomarkers as well as intermittent hyperglycemia. The possible mechanisms may be due to the effect of CRP and acute phase reaction proteins formed from different cytokines and counter-regulatory hormones released in critically ill patients [11] or may be due to the effect of elevated triglycerides levels during DKA that is through elevated levels of CRP, IL-6 via different complex mechanisms [14].

In the current study, there was a significant decrease of CRP levels in patients with DKA without infection after improvement of the Acute illness in comparison to its levels at time of admission $(P=0.054)$ was still higher than the CRP levels determined in control subjects with mean \pm SD $(17.13 \pm 24.66,2.02 \pm 1.25)$ respectively matching with a study done by Dragana et al. 2019 [15].

Elevation of circulating proinflammatory cytokines are reduced to normal levels promptly in response to insulin therapy and normalization of blood glucose concentration. Of interest, similarly high levels of these markers occurred in patients with DKA and non-ketotic hyperglycemia indicating that hyperglycemia, independent of the presence of ketoacidosis, induces changes in proinflammatory cytokines [16].

On the other hand, the levels of IL-6 were significantly decreased at time of DKA improvement rather than at time of admission $(P=0.001)$ especially after the start and intensification of insulin therapy which has a potent

Table 4 IL6 in patients before and after treatment

\begin{tabular}{llll}
\hline IL6 & $\begin{array}{l}\text { Before } \\
(n=30)\end{array}$ & $\begin{array}{l}\text { After } \\
(n=20)\end{array}$ & P value \\
\hline Mean \pm SD & $266.90 \pm 199.10$ & $74.82 \pm 106.98$ & 0.001 \\
Median (range) & $217.7(13.2-764.0)$ & $35.1(15.6-590.0)$ & \\
\hline
\end{tabular}




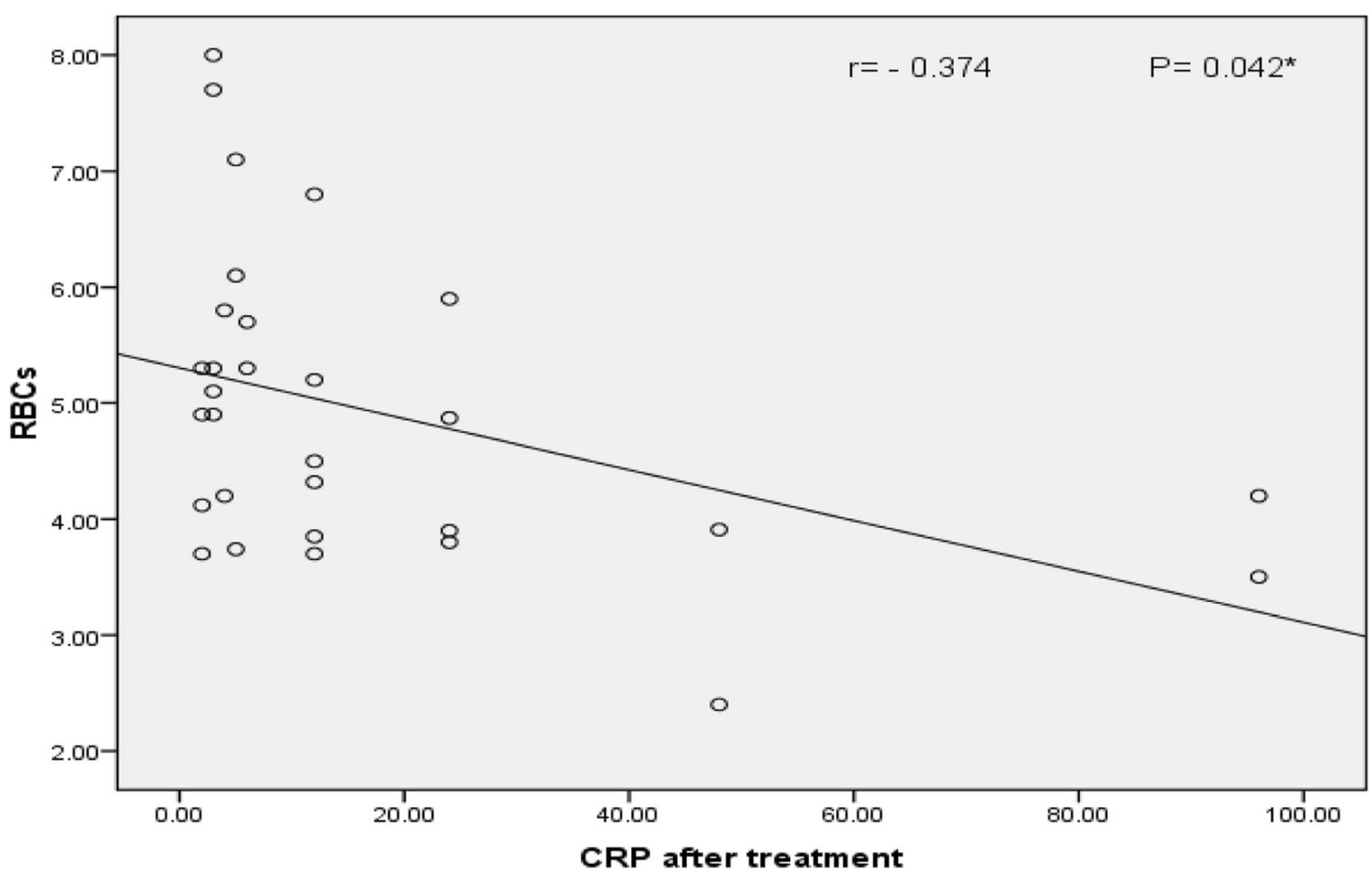

Fig. 8 Correlation between RBCs and CRP before treatment of DKA

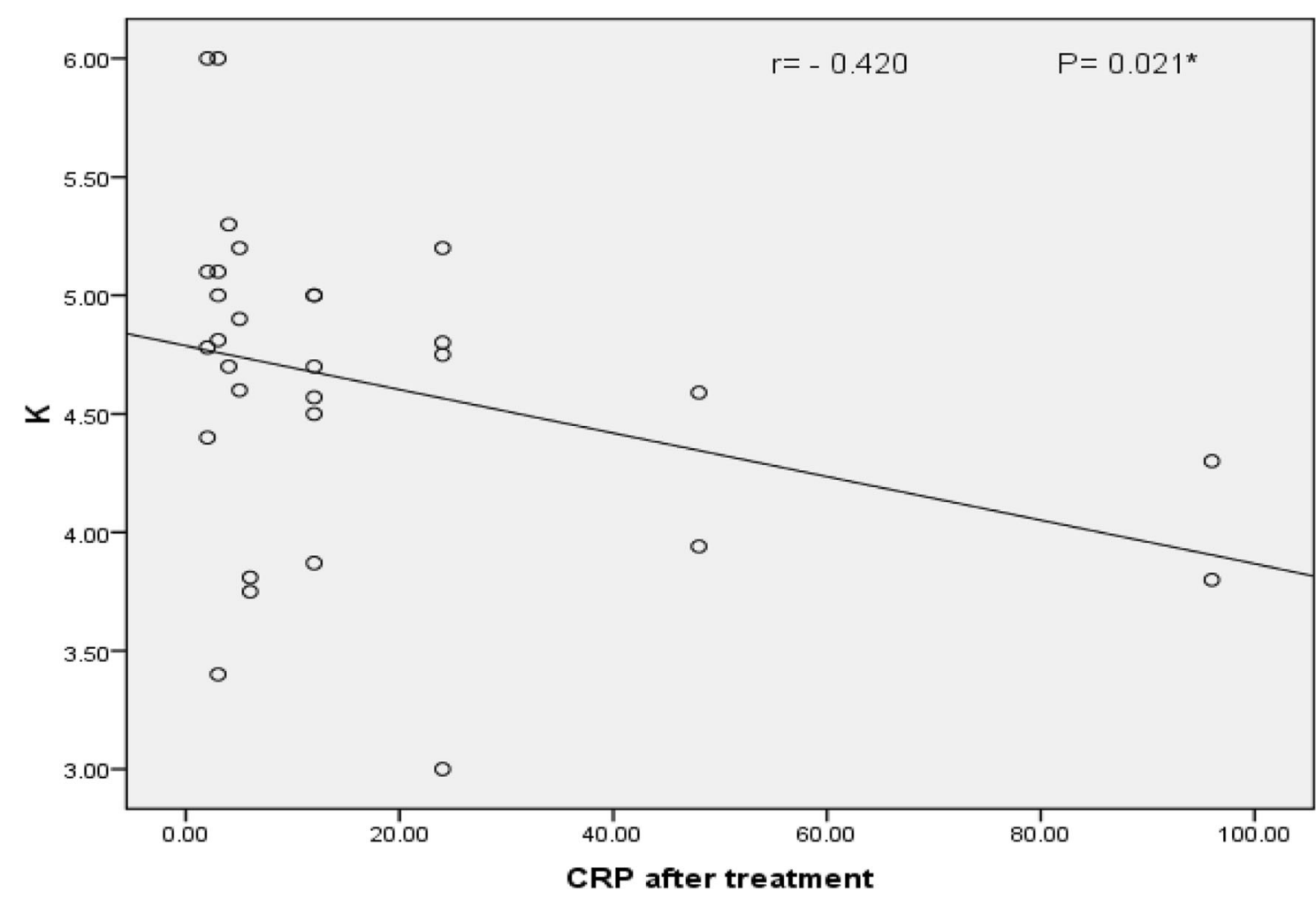

Fig. 9 Correlation between $\mathrm{K}$ level and CRP after treatment of DKA 


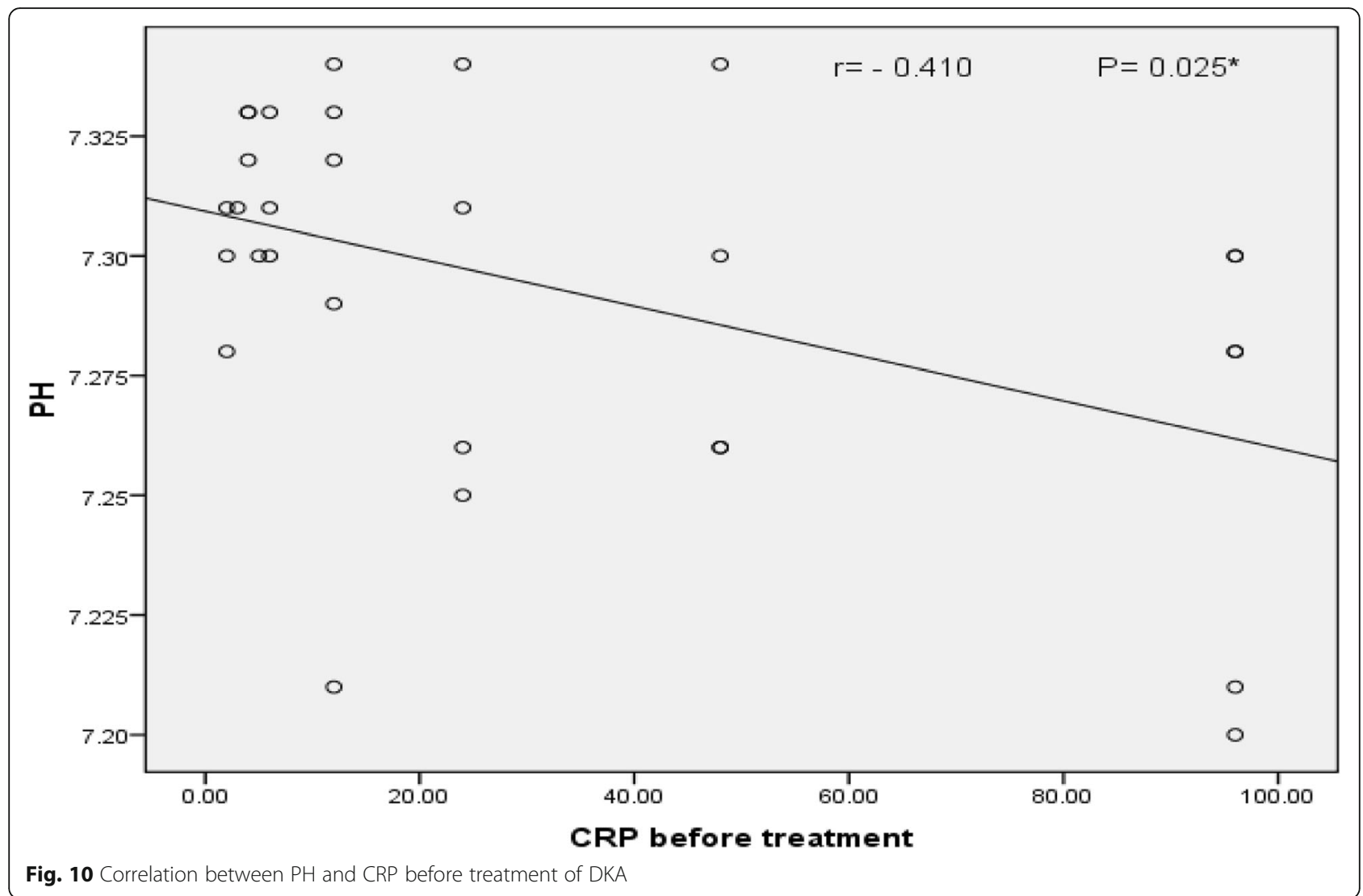

IL-6 lowering effect. Still, the IL-6 levels at time of improvement of DKA higher than in control subjects with mean $\pm \mathrm{SD}(74.82 \pm 106.98,0.73 \pm 0.74)$. Our results were in agreement with Esposito et al. and Kolb and Mandrup [17, 18].

Moreover, our results suggested that insulin therapy in these metabolic impairments has stronger beneficial effect and reduction of levels of IL-6 than on CRP with $P$ value $=0.001,0.054$, respectively.

We had a limited resource; so, we recruited all limited number of patients and we used non-parametric value in spite of parametric one. Future direction in our investigation will be to include a larger number of patients in each group which will add a strongest value to the research

Table 5 Correlation between IL6 before and after correction of DKA (Spearman)

\begin{tabular}{|c|c|c|c|c|}
\hline & \multicolumn{2}{|c|}{ IL6 before } & \multicolumn{2}{|l|}{ IL6 after } \\
\hline & $r$ value & $P$ value & rvalue & $P$ value \\
\hline WBC & -0.211 & 0.263 & -0.251 & 0.182 \\
\hline $\mathrm{RBC}$ & -0.010 & 0.956 & 0.163 & 0.388 \\
\hline $\mathrm{HB}$ & 0.045 & 0.815 & 0.105 & 0.582 \\
\hline R.B.S & -0.326 & 0.078 & 0.201 & 0.286 \\
\hline Acetone & -0.216 & 0.253 & 0.088 & 0.645 \\
\hline $\mathrm{PH}$ & 0.159 & 0.402 & 0.077 & 0.685 \\
\hline $\mathrm{HCO} 3$ & 0.091 & 0.634 & 0.043 & 0.821 \\
\hline Base efficiency & -0.322 & 0.083 & -0.047 & 0.804 \\
\hline Urea & -0.179 & 0.345 & -0.194 & 0.304 \\
\hline Creatinine & -0.348 & 0.060 & 0.001 & 0.996 \\
\hline $\mathrm{Na}$ & 0.151 & 0.425 & 0.134 & 0.480 \\
\hline K & -0.324 & 0.080 & 0.030 & 0.875 \\
\hline
\end{tabular}

WBCS white blood cells, RBCs red blood cells, HB hemoglobin level, R.B.S random blood sugar, Na sodium, $K$ potassium, HCO3 sodium bicarbonate, IL6 interleukin 6 


\section{Conclusions}

Patients with DKA without infection had elevated levels of CRP and inflammatory cytokines. Intensive insulin therapy has a strong anti-inflammatory effect that can normalize levels of CRP and inflammatory cytokines at time of DKA improvement, and this beneficial effect is stronger on IL-6 than on CRP.

\section{Abbreviations}

\%: Percentage; <: Less than; >: More than; ABG: Arterial blood gases; DM: Diabetes mellitus; CBC: Complete blood count; CRP: C-reactive protein; DHNK: Diabetic hyperosmolar non-ketotic coma; DKA: Diabetic ketoacidosis; ELISA: Enzyme-linked immunosorbent assay; IL-1: Interleukin-1; IL6: Interleukin-6; K: Potassium; Na: Sodium; SIR: Systemic inflammatory response; TNF-a: Tumor necrosis factor alpha; TIDM: Type 1 diabetes mellitus

\section{Acknowledgements}

To all mentioned authors only. Not applicable for any other researchers.

\section{Authors' contributions}

GM gave the idea of the research and design of the work part of the research and follow-up of patients in Assiut University Hospital, statistical analysis, and data reviewing and interpretation. MA was responsible for the laboratory part of the research (CRP and IL-6) and contributed to writing and data interpretation. RB contributed to writing, shared in clinical part of the research in Specialized Medical Hospital in Mansoura University, statistical analysis, and data reviewing and interpretation. AA contributed to writing (main role), shared in clinical part and follow-up of patients in Specialized Medical Hospital in Mansoura University, responsible for statistical analysis, and data reviewing and interpretation. All authors read and approved the final manuscript.

\section{Funding}

This research is not funded.

\section{Availability of data and materials}

The data that support the findings of this study are available from AA (corresponding author).

\section{Ethics approval and consent to participate}

It is not applicable. Prof. GA who is the first author confirmed that there was no ethical committee available during the start of our study; on the other hand, our subject did not receive any interventions or exceptional treatment during their stay in hospital, and the blood sample was aspirated during their routine investigations in the hospital after written and informed consents from all patients were included in our study Prof. GA took an oral approval from the head of the internal medicine department at the time of start of our study which was the accepted method at that time. Consent was taken from all participants.

\section{Consent for publication}

Taken from participants. All authors read and approved the final manuscript.

\section{Competing interests}

The authors declare that they have no competing interests.

\section{Author details}

${ }^{1}$ Faculty of Medicine, Assiut University, Assiut, Egypt. ${ }^{2}$ Endocrine and Diabetes Unit, Department of Internal Medicine, Faculty of Medicine, Mansoura University, Mansoura, Egypt. ${ }^{3}$ Endocrine and Diabetes Unit, Department of Internal Medicine, Mansoura Specialized Medical Hospital, Faculty of Medicine, Mansoura University, Mansoura, Egypt.

Received: 2 June 2020 Accepted: 27 July 2020

Published online: 15 December 2020

\section{References}

1. Kitabchi AE, Umpierrez GE, Miles JM, Fisher JN (2009) Hyperglycemic crises in adult patients with diabetes. Diabetes Care 32(7):1335-1343
2. Moshage $H$ (1997) Cytokines and the hepatic acute phase response. J Pathol 181(3):257-266

3. Burke AP, Tracy RP, Kolodgie F, Malcom GT, Zieske A, Kutys R et al (2002) Elevated C-reactive protein values and atherosclerosis in sudden coronary death: association with different pathologies. Circulation. 105(17):2019-2023

4. Di Napoli M, Papa F, Bocola V (2001) C-reactive protein in ischemic stroke: an independent prognostic factor. Stroke. 32(4):917-924

5. Pasceri V, Willerson JT, Yeh ET (2000) Direct proinflammatory effect of Creactive protein on human endothelial cells. Circulation. 102(18):2165-2168

6. Verma S, Wang CH, Li SH, Dumont AS, Fedak PW, Badiwala MV et al (2002) A self-fulfilling prophecy: C-reactive protein attenuates nitric oxide production and inhibits angiogenesis. Circulation. 106(8):913-919

7. Nooteboom A, Van Der Linden CJ, Hendriks T (2002) Tumor necrosis factoralpha and interleukin-1 beta mediate endothelial permeability induced by lipopolysaccharide-stimulated whole blood. Crit Care Med 30(9):2063-2068

8. Ciarla MV, Bocciarelli A, Di Gregorio S, Tordi A, Cotroneo P, Marra G et al (2001) Autoantibodies and endothelial dysfunction in well-controlled, uncomplicated insulin-dependent diabetes mellitus patients. Atherosclerosis. 158(1):241-246

9. King DE, Mainous AG 3rd, Buchanan TA, Pearson WS (2003) C-reactive protein and glycemic control in adults with diabetes. Diabetes Care 26(5): 1535-1539

10. Gogos CA, Giali S, Paliogianni F, Dimitracopoulos G, Bassaris HP, Vagenakis AG (2001) Interleukin-6 and C-reactive protein as early markers of sepsis in patients with diabetic ketoacidosis or hyperosmosis. Diabetologia. 44(8): 1011-1014

11. O'Riordain MG, Ross JA, Fearon KC, Maingay J, Farouk M, Garden OJ et al (1995) Insulin and counterregulatory hormones influence acute-phase protein production in human hepatocytes. Am J Phys 269(2 Pt 1):E323-E330

12. Aljada A, Ghanim H, Mohanty P, Kapur N, Dandona P (2002) Insulin inhibits the pro-inflammatory transcription factor early growth response gene-1 (Egr)-1 expression in mononuclear cells (MNC) and reduces plasma tissue factor (TF) and plasminogen activator inhibitor-1 (PAl-1) concentrations. J Clin Endocrinol Metab 87(3):1419-1422

13. Rolla A (2004) The pathophysiological basis for intensive insulin replacement. Int J Obes Relat Metab Disord 28(Suppl 2):S3-S7

14. Jonkers IJ, Mohrschladt MF, Westendorp RG, van der Laarse A, Smelt AH (2002) Severe hypertriglyceridemia with insulin resistance is associated with systemic inflammation: reversal with bezafibrate therapy in a randomized controlled trial. Am J Med 112(4):275-280

15. Popovic D, Lalic K, Jotic A, Milicic T, Bogdanovic J, Dordevic M et al (2019) The inflammatory and hemostatic cardiovascular risk markers during acute hyperglycemic crisis in type 1 and type 2 diabetes. J Med Biochem 38(2): 126-133

16. Stentz FB, Umpierrez GE, Cuervo R, Kitabchi AE (2004) Proinflammatory cytokines, markers of cardiovascular risks, oxidative stress, and lipid peroxidation in patients with hyperglycemic crises. Diabetes. 53(8):2079-2086

17. Esposito K, Nappo F, Marfella R, Giugliano G, Giugliano F, Ciotola M et al (2002) Inflammatory cytokine concentrations are acutely increased by hyperglycemia in humans: role of oxidative stress. Circulation. 106(16):2067-2072

18. Kolb H, Mandrup-Poulsen T (2005) An immune origin of type 2 diabetes? Diabetologia. 48(6):1038-1050

\section{Publisher's Note}

Springer Nature remains neutral with regard to jurisdictional claims in published maps and institutional affiliations. 